\title{
Impact of mergers and acquisitions on companies' financial performance
}

\author{
Alex Borodin \\ Department of Finance, \\ Plekhanov Russian University of Economics, \\ Russia \\ aib-2004@yandex.ru
}

\section{Sayabek Ziyadin}

Korkyt ata Kyzylorda State University,

Kazakhstan

sayabek.z@gmail.com

\section{Gulnara Islyam}

The Faculty of Economic Sciences,

Serikbayev East-Kazakhstan State University Oskemen,

Kazakhstan

ertis economika@mail.ru

\section{Galina Panaedova}

The Faculty of Economic Sciences,

North-Caucasus Federal University,

Russia

afina-02@rambler.ru

Abstract. This paper explores the influence of M\&A transactions on the financial performance of US and European companies. We have studied the sample of 138 M\&A transactions performed within these two regions during the period between 2014 and 2018. We investigate the correlation between return on sales (ROS) and such variables as equity-to-enterprise value ratio. Moreover, we observe the impact of the financial crisis and industry-relatedness to M\&A parties on the performance of a merged company. Most of the corporations studied both in the USA and in Europe were profitable, and remained so after mergers and acquisitions. However, despite the fact that positive values were found for the studied variables, tests for the analysis of average values in the sample show a significant deterioration in ROS in both regions. At the same time, in the USA the change in the EBIT/Total Revenue ratio averaged $-6.8 \%$, and in the European countries $-5.3 \%$. Regression analysis did not reveal a significant relationship between mergers and acquisitions and company performance 
indicators, and the difference in values by region can be interpreted by the fact that the US entered the crisis at an earlier point in time. The significance and the sign of the EVEQ coefficient indicate that, ceteris paribus, an increase in the "attractiveness" of target companies leads to an increase in ROS. The results do not indicate any particular impact of M\&A on post-M\&A performance in the companies considered.

Keywords: corporate finance, mergers and acquisitions, M\&A deals, ROS, company.

JEL Classification: F53, O51, O52

\section{INTRODUCTION}

It is difficult to overstate the importance of multinational companies to today's global economy. For instance, by the end of 2017 , the total revenue generated by the world's largest 500 corporations $(\$ 27.6$ billion), as represented in the Fortune Global 500, accounted for almost 37\% of Gross World Product ( $\$ 75.2$ billion). Multinationals are becoming the most significant component of the global economy and are the engine driving evolution and technological progress. One of the key points of concern amongst executives is how to maintain sustainable growth and the leading role such international actors might play in the future. In order to accelerate corporate development processes and to react to changes in the competitive landscape, some top managers have resorted to tactics such as corporate restructuring, which largely involves mergers and acquisitions $(M \& A)$ and leads to changes in organisational structure, the legal form of an enterprise and its performance.

In 2014, McKinsey \& Company found that about $85 \%$ of the enterprises with capital of over $\$ 1$ billion in developing countries are family owned. The associated shares of this nature are about $75 \%$ in Latin America, 67\% in India and 65\% in the Middle East. China, where this proportion is about $40 \%$, and subSaharan African countries (35\%) are distinguished by their relatively low shares of family-owned firms, since in both cases many of these countries' larger firms belong to the state (Kokoulina, 2017). At present, researchers note that there have been seven waves of M\&A activity, which means that such businesses have been evolving with the passage of time, and the existence of different types of M\&A transactions confirms this information.

The aim of this work is to analyse how mergers and acquisitions affect post-transaction corporate performance. Moreover, the question as to why companies continue to employ this method to enhance productivity remains open. There have been a great number of such transactions that have performed well; however, historical evidence also suggests there to be a large number of poor M\&As (Mourdoukoutas, 2011). Hence, it is important to understand how performance varies according to circumstances.

\section{LITERATURE REVIEW}

According to some of the previous studies concerning the impact of M\&A transactions on the financial performance of companies, the nature of mergers and acquisitions is quite complex and, indeed, apparently contradictory. Some of these studies have indicated the positive impact of such activities on the economic efficiency of a number of companies (Kinateder et al., 2017; Blomson, 2016; Betzer et al., 2015), whilst others suggest mergers and acquisitions have had an entirely negative impact (Ayadi et al., 2014; Borodin et al., 2019; Tang, 2015), or are otherwise negligible (Andreu \& Sarto, 2013; Campello, 2018). Historically, economists and researchers from around the world have analysed various aspects of M\&A deals in the 
attempt to come to a clear understanding of the impact of this phenomenon on the economic efficiency of enterprises, but to date any associated consensus has yet to be reached.

M. Campello and colleagues (2018) noted that there are certain specific effects of short selling constraints on corporate policies, and empirically showed how the equity-lending market affects corporate behaviour. They considered 56 mergers conducted amongst Spanish investment funds between 2016 and 2018. Scientists have concluded that mergers and acquisitions, in general, have a negligible effect on the performance of investment funds. It should be further noted that despite the fact that prior to acquisition target companies tended to have lower economic performance than their acquirers, the data on the final companies (created as a result of the M\&A) does not allow one to draw definitive conclusions about the difference in cost-effectiveness of acquiring companies before and after the completion of such transactions (Andreu \& Sarto, 2013).

Empirical studies by A. Betzer, M. Doumet, and M. Goergen (2015) concentrated on the analysis of wealth effects after mergers and acquisitions based on data concerning share price fluctuations and changes in chosen performance indicators. They divided all the investigated transactions into four distinct groups. The first and the fourth groups included those mergers and acquisitions that both times showed positive changes in stock price and in the observed measure or measures from the financial statement (group I), or which in both cases were negative (group IV). Groups II and III included M\&As that gave the opposite results (positive share price change in parallel with negative change in financial statement measure, and vice versa, respectively). By comparing these groups, researchers noticed that the most typical method of financing for sample I was "cash". Group I can also be characterised by positive expectations regarding the associated effectiveness. Group II is described as a particular set of transactions that have been performed in order to prevent similar actions by competitors. The "stock" method of financing turned out to be a more popular approach than "cash" in the third group. In group IV, and indeed in group III, "stock" financing was frequently observed. When researchers considered the entire sample, they noted that it was dominated by companies that showed increased observed financial indicators post-M\&A (Betzer et al., 2015).

In this study, the same performance indicators as those observed by M. Blomson (2016) were found. Moreover, the regression model is similar to the model employed by H. Kinateder, M. Fabich, and N. Wagner (2017). In addition to conventional methods, the impact of mergers and acquisitions was analysed by means of a non-traditional method referred to as "economic profit". After reviewing the results of their regressions, these researchers concluded that the financial performance of the companies concerned actually declined; the "Economic profit" model analysis gave similar results ("median industry-adjusted economic profit" reduced by $\$ 4$ million after the deal) (Borodin et al., 2019).

H. Kinateder, M. Fabich, and N. Wagner (2017) were amongst the first to perform a regression analysis of the cost-effectiveness of mergers and acquisitions. They conducted a study of 50 of the largest transactions realised between 2014 and 2016, concluding that operating cash flows improved after the completion of M\&A transactions. It is important to note that these authors pointed to the direct impact of improved asset productivity in the cash flow performance of companies (Kinateder et al., 2017).

In 2016, scientists K. Uhlenbruck, M. Hughes-Morgan, and M. A. Hitt (2016) investigated a sample of 859 transactions that occurred between 2014 and 2016. The objective of their study was to analyse the mutual influence of such factors as (1) a method of financing, (2) the distortion of financial statements, and (3) the operating efficiency of companies. Based on their results, Heron and Lie came to the conclusion that the method of funding does not affect the post-M\&A efficiency of a given transaction or, indeed, the discretionary accruals, but after the announcement the company stock price was lower for deals that used the "stock" method of financing compared to those using "cash". As for the overall impact of M\&A transactions on economic performance indicators, the researchers found significant improvements in the 
observed parameters after corporate transactions compared with the average for the industry (Uhlenbruck et al., 2016).

D. Gabor (2016) examined a sample of 35 M\&A transactions focussing on the European Commission's proposals to include the repo market - a market systemic to European (shadow) banking - in the financial transactions tax (2016). Scientists employed the same methodology as K. Uhlenbruck and M. HughesMorgan (2016), but preference was given to the analysis of cash flow figures. Regression results showed that increased "cost-efficiency" and synergy were offset by a fall in industry-adjusted variables. The correlation between the post-M\&A efficiency of the companies and changes in share prices after the announcement of such transactions was not revealed in the study (Gabor, 2016).

A. Balcerzak et al (2017) and K. Valaskova et al. (2018) propose a methodology for a comprehensive evaluation of operational efficiency of the banking sectors in EU countries. Also authors measure the degree of inefficiency of banking sectors in the "new" and "old" EU countries.

In 2014, R. Ayadi and W. De Groen (2014) initiated an annual monitoring exercise of banking business models in the EU. The researchers noted that the process of adjustment of chosen financial statement measures could be a major reason for the fact that the results of related studies frequently differ from each other. For example, the authors pointed out that industry-adjusted indicators grow, while industry, size and performance-adjusted measures decrease. It must be emphasised that as hostile takeovers tender - negatively correlate with the tested measures (Ayadi et al., 2014).

It has been concluded that synergies obtained from combining innovation capabilities are important drivers of acquisitions, as described in the work by J. Bena and K. Li (2014). This study was the most extensive of all of the above papers in terms of number of indicators analysed. Contrary to the opinion held by Ayadi (2014), no significant impact of the process of adjustment was found by this study. The "change" model outcome also revealed an increase in the efficiency of economic performance amongst firms after M\&A (Bena \& Li, 2014).

M. A. Hitt continued the study of K. Uhlenbruck and M. Hughes-Morgan (2016), considering 324 US mergers and acquisitions. Hitt came to the conclusion that the economic performance of the firms formed as a result of M\&A tended to increase. The correlation between such factors as the size of the transaction, industry and debt-to-equity ratio was not found to be significant. Hitt agreed with the idea that in most cases M\&As are motivated by the anticipated synergy (Hitt, 2016).

The financial sector of the Philippines was analysed in the work of E. Tang. The exact number of observed transactions was not specified, but the author's analysis included all mergers and acquisitions that took place at the Philippines. Regarding the motives for transactions, Tang pointed out that in this sector M\&As mainly aim to achieve synergy and economies of scale, challenging the assertion that the inclusion of traditional financial indicators (ROA, ROE, ROS, and so on.) creates problems for the analysis instead of providing answers to the issues raised. The author also expressed the view that traditional measures can be used to accurately assess the effects of M\&As. The results of the research showed a significant deterioration in ROA after M\&A transactions and the absence of significant changes in AROA (Tang, 2015).

Many other scientists have considered these problems, such as Simionescu et al. (2017). Some authors studied as determinants of economic growth in V4 countries. When studying competition between Londonbased companies with regard to their financial performance, there was a merger of companies (Simionescu, 2016). Some authors saw this problem through the lens of sustainable economic development, whilst others saw it through that of social entrepreneurship (Bilan et al., 2017). Mergers and acquisitions are strongly influenced by human capital and entrepreneurial competencies for the development of informal microenterprises (Zainol et al., 2018). Such trends were even considered to be the impact of innovation and innovative behaviour on the activities of travel companies (Domi et al., 2019). 


\section{DATA END METHODOLOGY}

The study represents a comparison of regression analysis and two Student's t-tests performed on the basis of data on 138 M\&As between companies from the US or from the European region between 2016 and 2018 .

\section{Sample}

In order to form a sample, only those transactions that satisfy the following criteria were selected ${ }^{1}$ :

1. Committed either between companies from the US, or between companies from Europe;

2. Successfully completed;

3. Executed in the time interval between $01 / 01 / 2016$ and 31/12/2018;

4. Data on both parties is available for the year before and two years after the execution of the transaction;

5 . At least $50 \%$ of the shares of the target company were acquired;

6. Minimum value of the transaction was $\$ 150$ million.

Accordingly, the final sample includes 138 mergers and acquisitions.

Restrictions on the minimum transaction value and the minimum percentage of repurchased shares were introduced in order to select only those companies that could, in our opinion, more clearly demonstrate the effect of the transaction.

The Thomson Reuters Advanced Analytics database was used to collect information.

The preliminary sample consisted of 156 transactions, including 65 European transactions and 91 American transactions.

The ratio of the average Return On Sales (ROS) for the absorbing company for two years after the transaction was chosen as the analysed indicator.

In addition, as a descriptive variable for the Intercept model, the Equity Value/Enterprise Value ratio (hereinafter, EVEQ) was added to the Pre-M\&A ROS, the dummy of companies belonging to the same microindustry, and the dummy of the crisis. These indicators are actively used in analysing the value of companies. The magnitude of the Equity Value (Eq. Val.) shows the total value of common shares, while the Enterprise Value (Ent. Val.) shows the total cost of the company itself.

This ratio was added for the purpose of verifying and evaluating the impact of a give company's market capitalisation ratio and its sale price on the subsequent performance of the final firm after the M\&A transaction.

Further, box charts and histograms were constructed for each region based on the average ROS for two years after the transaction, the total for the buyer company and the target company ROS before the transaction, and for the EVEQ indicator for the total sample (Fig. 1).

1 All data were taken from Thomson One database. 

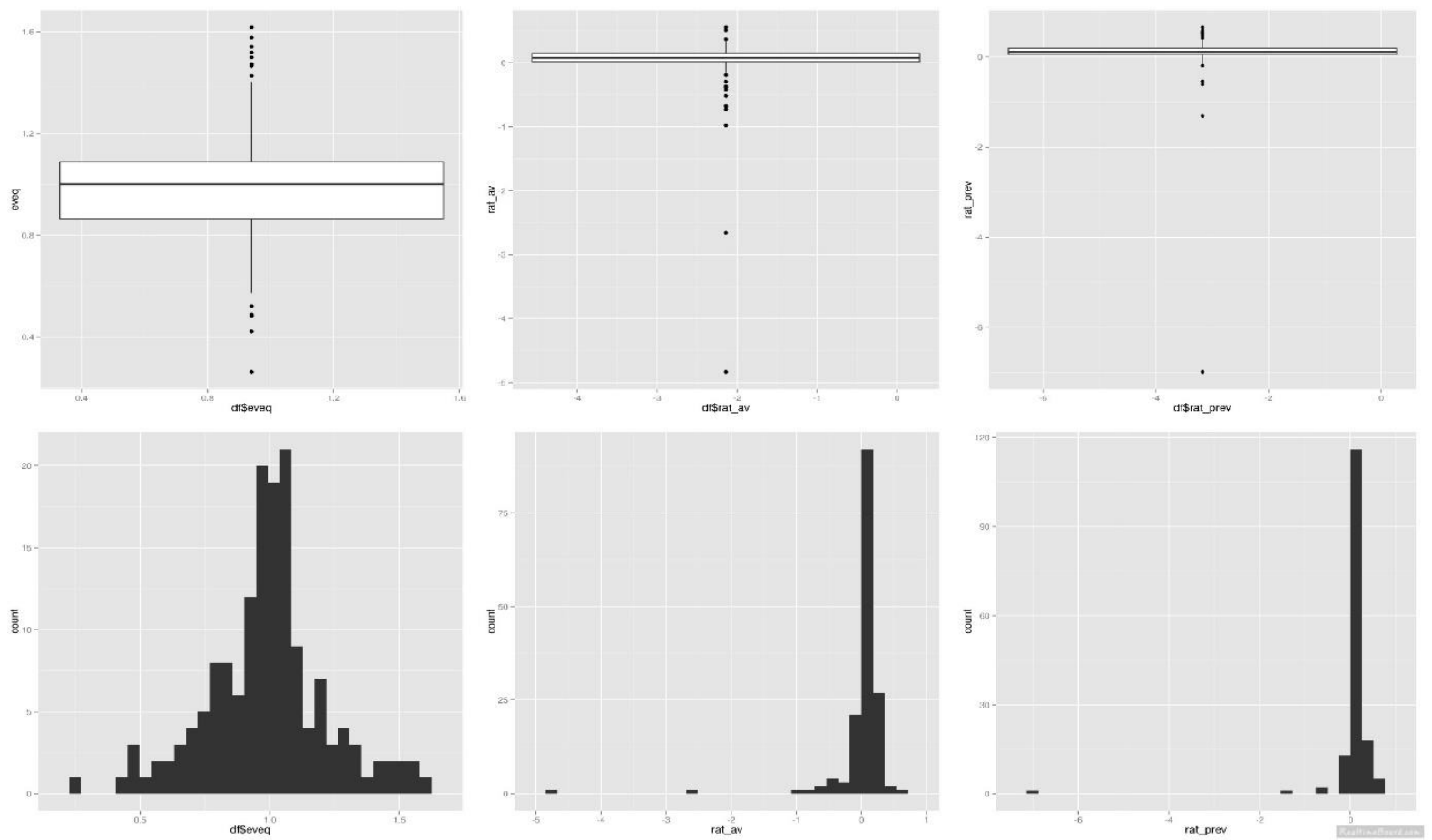

Figure 1. Box charts and histograms for EVEQ, Pre-M\&A ROS (rat_prev), Av indicators. PostM\&A ROS (rat_av) for general selection before deleting outliers

As can be seen from the graphs, the EVEQ index for most companies in the sample was more than one, which can indicate both the structure of assets of the acquired companies (debt obligations $=0$, and cash and cash equivalents exceed the total value of preferred shares and minority shareholders' shares), and that the companies were profitable for the transaction since their capitalisation exceeded their value.

It is proposed to consider this variable from the point of view of the "attractiveness" of the target company (if the ratio is greater than one, then the company is more attractive than if it were less than one).

The average ROS before the transaction is completed exceeds the average ROS after it is completed.

In addition, when looking at these figures, one can see that there are companies in the sample whose values are strongly distinguished; this can be seen from both box charts and histograms. For this reason, 18 outliers were found in the sample and then deleted.

Figure 2 and Figure 3 show box charts, histograms, as well as scatter plots for Europe and the United States for the above-listed indicators. 

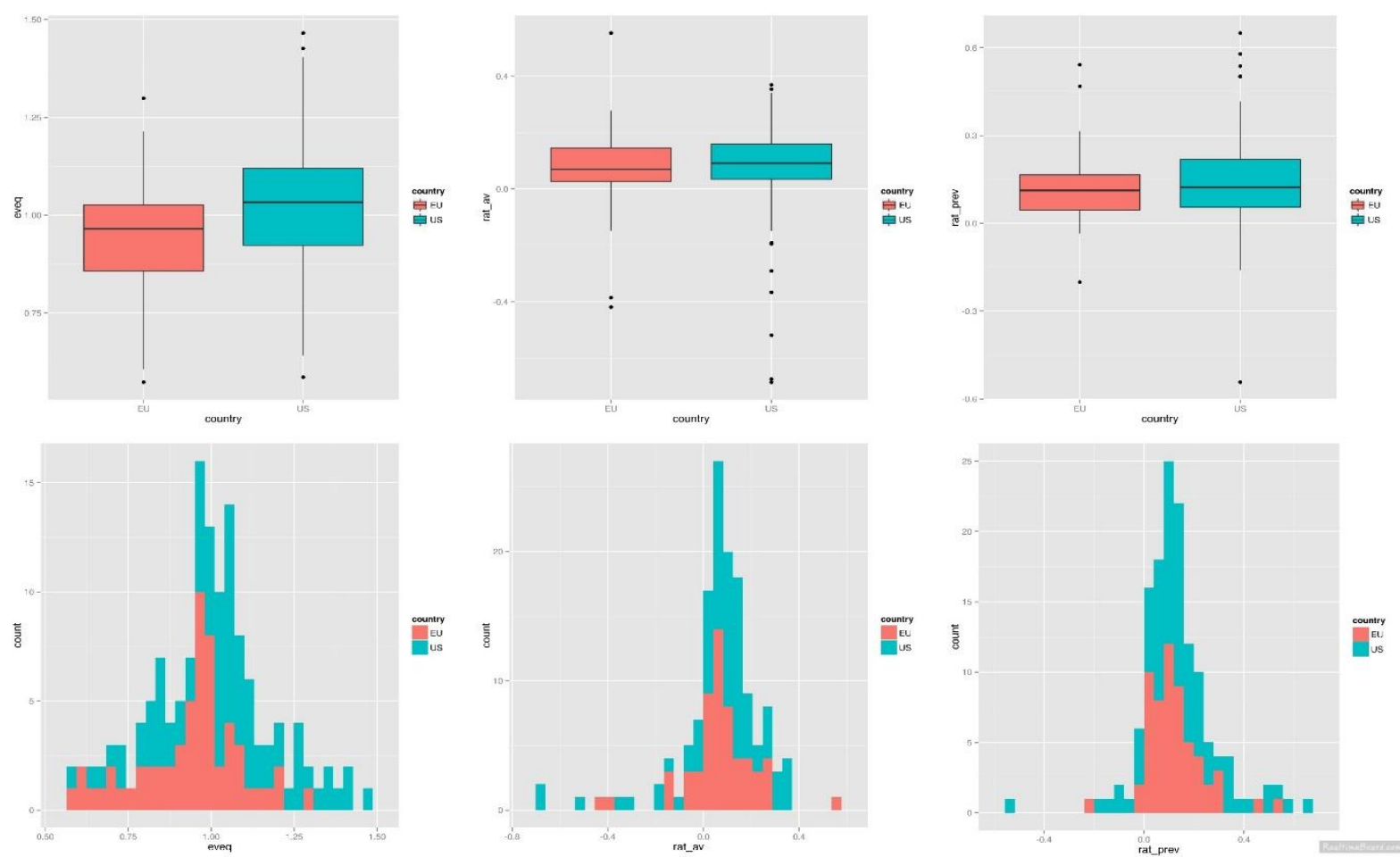

Figure 2. Box charts and histograms for EVEQ, Pre-, Av indicators. Post-M\&A ROS (rat prev, rat_av) for Europe (EU) and the USA (US) after outlier removal

Based on the study of the graphical presentation of the data under study, the following preliminary conclusions can be drawn:

1. Transactions conducted in the United States have a higher EVEQ ratio than transactions conducted in Europe;

2. Both American and European companies show a significant decrease in ROS;

3. Both regions (the United States and European countries) have fairly similar statistical distributions for each measure;

4. There is a clear correlation between ROS indicators before and after the transaction for both regions;

5. The number of companies that had a profitable ROS before the M\&A transaction, and after it became unprofitable, is distributed in approximately equal proportions for both the US and Europe;

6. Among those companies that were unprofitable and remained so, firms from the United States dominate. There is only one such company in Europe;

7. Companies that were unprofitable before $M \& A$ and became profitable after they were completed were distributed in a relatively equal proportion, as well as those that were profitable before the transactions and became unprofitable after the completion of mergers and acquisitions.

8. Most firms were profitable before making deals, and remained so after M\&A. 

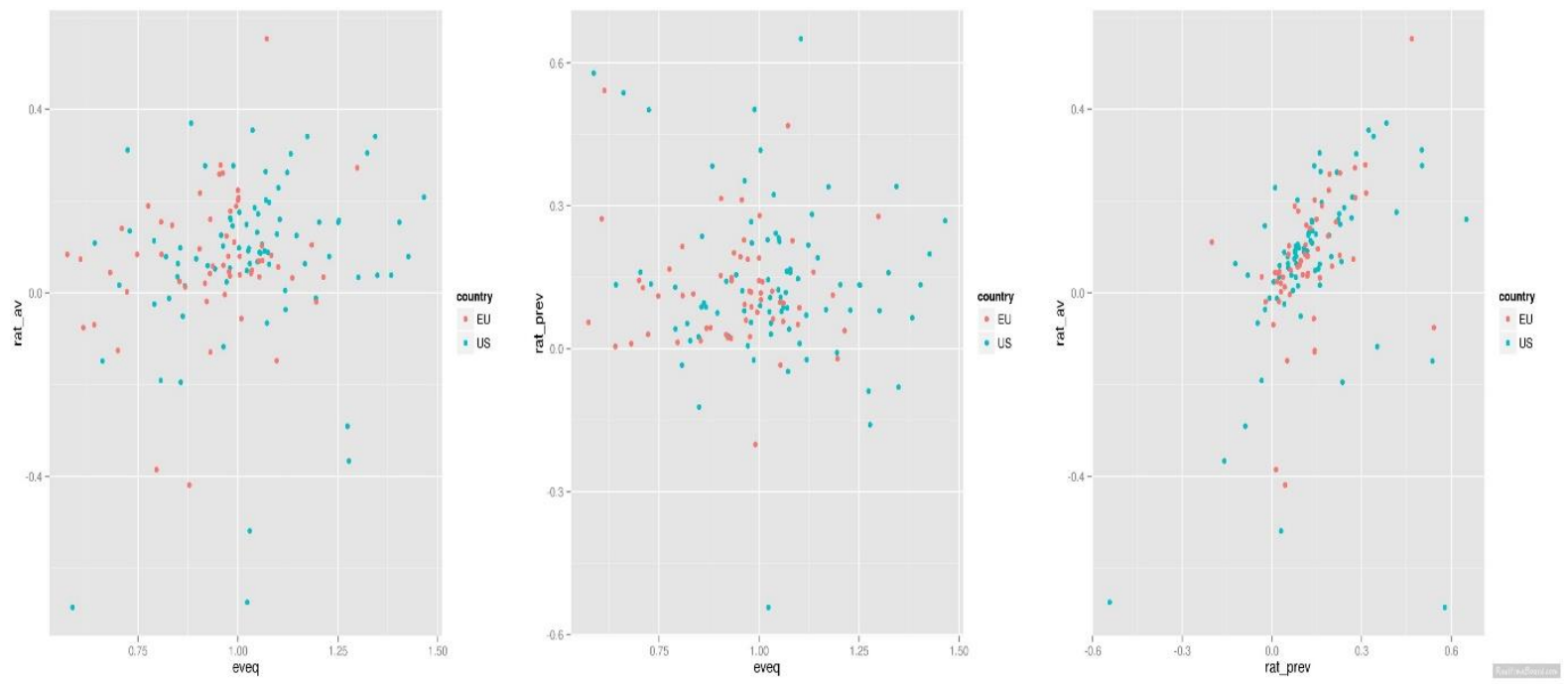

Figure 3. Scatter plots of EVEQ, Pre-, \& Av indicators. Post-M\&A ROS (rat_prev, rat_av)

One of the most important aspects of research is the choice of financial indicators to analyse. The article considers some indicators of accounting statements of companies that have been studied in work on similar topics and will be used in the model of this study.

1. Operating profit (EBIT).

Operating profit is calculated as the difference between income and expenses:

EBIT $=$ Revenue-Costs of products sold-Operating costs-depreciation and amortisation Costs

2. Operating profit including depreciation and amortisation (EBITDA).

EBITDA $=$ EBIT + depreciation and amortisation costs

EBIT and EBITDA are among the most commonly used indicators for analysing M\&A transactions. However, these measures have some drawbacks. For example, the fact that they are not GAAP indicators means that there is no standard method for calculating this measure, i.e., its official calculation may vary depending on the company in question's policy.

3. Pre-tax operating cash flow (pre-tax OCF) is calculated using the following formula:

Pre-tax OCF $=$ Revenue-product costs - sales costs -

administrative expenses + depreciation and amortisation + expenses on intangible assets

4. "Net" operating cash flow ("pure" OCF)

The difference between pre-tax OCF and "pure" OCF is that the latter indicator depends on the research methodology, but usually "net" flows include changes in inventory and accounts receivable.

Research economists Powell and Stark define this indicator as EBIT adjusted for working capital dynamics.

5. Return on assets ratio $(\mathrm{ROA})$ :

Return on Assets $=$ EBIT $/$ (Average Total Assets)

When analysing the effectiveness of M\&A transactions, the ROA indicator is considered one of the most actively used, and objectively reflects the effectiveness of transactions.

This indicator includes the previously described EBIT, which is an indicator of the company's operating profit, as well as the average total assets that must be taken into account when performing mergers and acquisitions. 
In addition to ROA, similar measures (ROE or ROS) can be used, calculated as EBIT/Equity (ROE) and EBIT/Revenue (ROS).

To analyse the selected data for our 138 transactions, we used the Intercept model and two tests for the Student's t-test to examine the following hypotheses:

H1: Mergers and acquisitions have a positive impact on financial performance after transactions in both Europe and the United States;

H2: the Crisis has a negative impact on the studied indicator in at least one of the regions.

The H1 hypothesis is tested by both regressions and tests using the Student's t-test. To confirm the hypothesis, it is necessary that the regression, which has only the ROS indicator as an explanatory variable before the transaction, is significant. In addition, the intercept must be significant and have a positive coefficient. If these conditions are met, then for additional verification, the average value of each sample (both in Europe and the United States) must be greater than zero based on the results of the two tests.

If these two conditions are met, the hypothesis is confirmed. If any of the conditions are not met, the hypothesis is rejected.

To analyse the hypothesis about the impact of the fact of the crisis on the studied indicator, only regression analysis is performed. To confirm this hypothesis, the regressions must be significant, and in at least one of the countries, the coefficient for the dump of the crisis variable must have a negative sign.

\section{Models}

The first model employed in this study examines the correlation between the observed financial measure (Post-M\&A ROS) and the fact of the execution of the transaction being as follows:

$$
\mathrm{ROS}_{\text {Post-M } \& A}=\beta_{0}+\beta_{1} \cdot \mathrm{ROS}_{\mathrm{Pre}-\mathrm{M} \& A}+\varepsilon
$$

In this case, $\beta_{0}$ shows how the effects produced by the fact of M\&A execution are correlated with the analysed measure.

The second model is designed to evaluate the correlation between post-M\&A ROS and the following variables:

Pre-M\&A ROS;

Equity value-to-enterprise value ratio ${ }^{2}$;

Method of payment (dummy): 1 - mixed, 2 - cash, 3 - stock;

Crisis (dummy): 1 - deal completed in 2017 or 2018, 0 - completed in 2016;

Industry-relatedness (dummy): 1 - both parties to the transaction operate in the same microindustry, 0 - different microindustries.

Thus, the second model is as follows:

$$
\begin{aligned}
\operatorname{ROS}_{1,2}^{\text {post M\&A }}=\beta_{0} * \operatorname{ROS}_{-1}^{\text {preM\&A }}+\beta_{1} * \frac{\text { Eq.Val }}{\text { Ent.Val }}+\gamma_{0} * \text { MOP } & +\gamma_{1} * \text { CRISIS }+ \\
& +\gamma_{2} * \text { INDUSTRY }
\end{aligned}
$$

\footnotetext{
2 Equity value to enterprise value (EVEQ) is considered an indicator of the attractiveness of a company since the ratio shows the extent to which the market value of a corporation correlates with its book value. The greater the ratio, the greater the "attractiveness" of a company is.
} 


\section{EMPIRICAL RESULTS AND DISCUSSION}

The results of the regression-based analysis are represented in Table 1 and Table 2. Shapiro-Wilk and Breusch-Pagan tests have been successfully completed. All regressions are statistically significant.

The first model [see Table 1] shows that the intercept $\left(\beta_{0}\right)$ is insignificant in both cases. Therefore, the impact of mergers and acquisitions on the observed variable is unascertained by the model. The H1 hypothesis is rejected at the first stage.

The second model [see Table 2] reveals a notable correlation between pre- and post-M\&A ROS (the first model also confirmed this), both for the European region and for the United States. This fact supports the earlier implication, as based on the scatter plot analysis. Moreover, the rate of EVEQ is significant at 0.1 and it has a positive relationship with ROS after the deal in both cases.

Table 1

Model 1 OLS Regression results

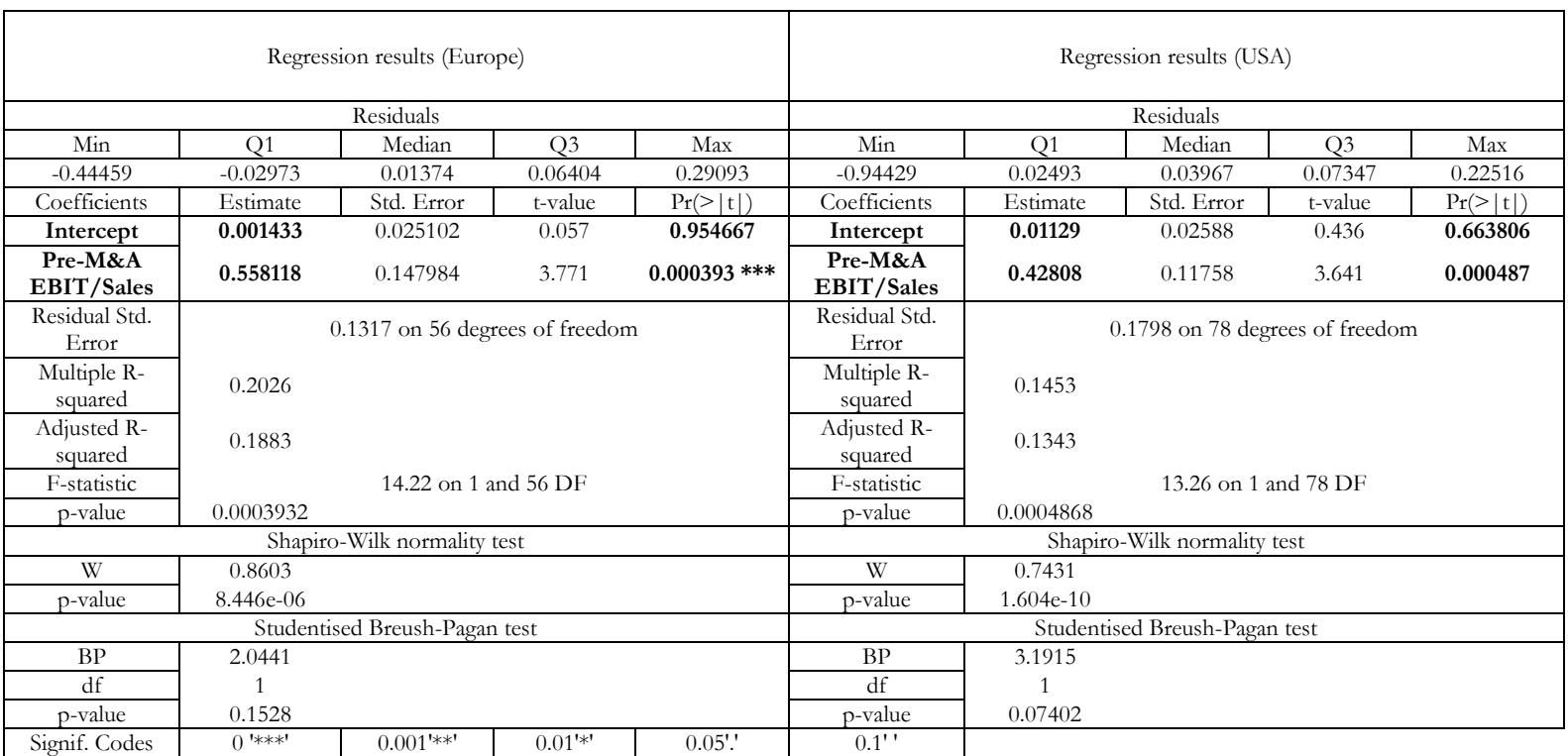

Method of payment, crisis and industry-relatedness coefficients differ depending on the region. For the European deals, the "mixed" (significant at 0.05) and "stock" (significant at 0.01) methods of payment turned out to be statistically significant and negatively correlated with the observed measure. The other variables in the regression (European deals) were not statistically significant. However, the significance levels of the "cash" method and industry relatedness in the European sample are close to 0.1. Thus, there is a high probability that with an increase in the size of the sample, these variables will become significant. Thus, the $\mathrm{H} 2$ hypothesis is confirmed.

In the US, all methods of payment are significant (at 0.05) with negative coefficients. The industryrelatedness dummy is not statistically significant, while the model found a slight negative impact of crisis on post-M\&A ROS. 
Model 2 OLS Regression results

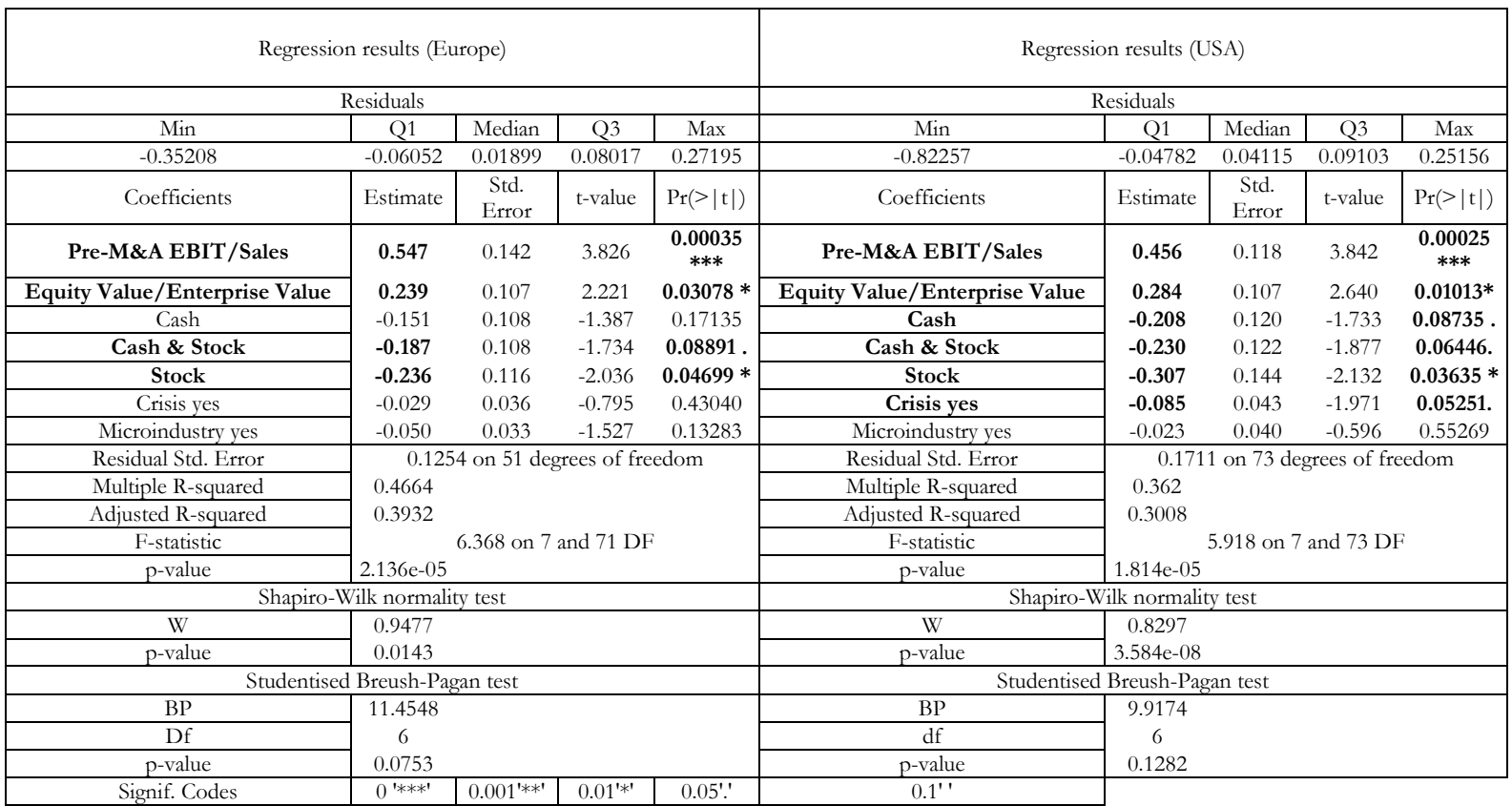

The results of the two Student's t-tests are given in [Table 3]. The data here allows us to compare changes in average ROS values before and after M\&As. Both tests identified a deterioration in the difference between pre-M\&A and post-M\&A ROS.

Thus, the results of these models and tests show a significant deterioration of ROS after M\&As, despite the fact that the majority of investigated corporations from the US or Europe retained positive ROSs. In the US and in Europe, the EBIT-to-total revenue ratio average change was $-6.8 \%$ and -5.3\%, respectively.

The significance level and the sign of a coefficient EVEQ indicate that the increase of the "attractiveness" of the target companies leads to an increase in ROS of the merged corporations after the deal.

At the same time, without additional calculations one cannot draw further conclusions concerning the relationship between the methods of payment used in the transactions and the financial performance of the observed companies, as the model only allows the comparison of these methods with each other. In general, when the acquirer finances the deal with "cash", the productivity of the post-M\&A corporation is greater than for "stock" or "mixed" financing. This conclusion coincides with Betzer's opinion (Betzer et al., 2014). It can be assumed that the attractiveness of the "cash" method is due to the fact that it is often used by prosperous companies that are able to generate abundant cash inflows. 
One-Sample t-test results for both regions

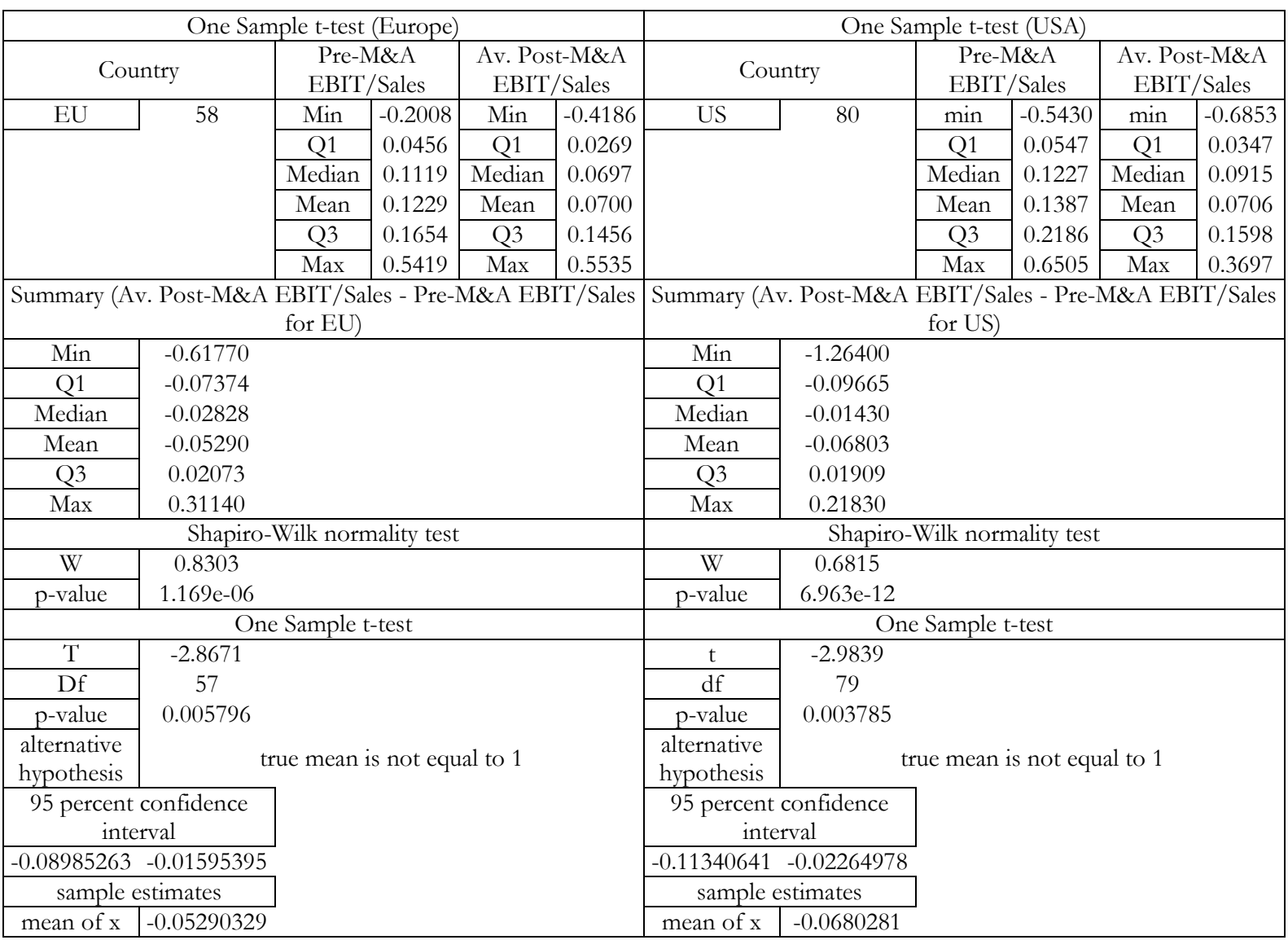

\section{Managerial implication}

The findings can also be interpreted in the instance of management decisions. One of the most important questions for top management is whether M\&As are worthwhile or otherwise. The answer is somewhat difficult to generalise, however, since each deal has its own particularities. When we talk about the whole sample, the results show that in most cases the final companies remained profitable and, from this perspective at least, M\&As are worthwhile, though some companies that were profitable before the deal became lossmakers in terms of ROS. It is also important to note that the decrease (in comparison to ROS pre-M\&A) of ROS post-M\&A can be the result of various factors such as business reorganisation, crisis (even if the model did not reveal its influence), business depression, etc., which can be offset in the long term.

\section{CONCLUSION}

In conclusion, it should be noted that M\&As are complex phenomena, and which have accordingly been the subject of research for many years. Analysis of the fluctuations of financial activity related to M\&A transaction participants in the US and in other regions have shown that, today, seven distinct waves of such can be identified, as characterised by the changes in the volumes of such transactions on a year-by-year basis. Each of these cycles has its own time frame, which usually begins in times of economic recovery from a crisis that marks the ending of the previous cycle. In addition, each wave is associated with the emergence 
or development of new characteristics of mergers and acquisitions or the emergence of new economically sound reasons for pursuing them.

This paper investigates 138 cases of mergers and acquisitions committed between 2016 and 2018 between companies headquartered in either the US or Europe.

The results of the models and tests designed have shown that in both regions corporations that were profitable before M\&As maintained positive financial performance after the deals. Nevertheless, these companies showed a significant deterioration in ROS after the implementation of mergers and acquisitions. In addition, the first model constructed shows that mergers and acquisitions does not have a significant effect on the profitability indicator of the selected companies.

It should be added that there is a significant but small impact on the ROS of the US companies, which may explain a relatively greater reduction in efficiency in the US rather than in Europe.

As for methods of payment, the data shows that the use of the "cash" method typically leads to a higher ROS after M\&As than "mixed" or "stock" financing.

It is also important to note that a number of limitations were imposed on the analysis. These constraints only allow us to draw conclusions concerning certain types of transactions.

\section{REFERENCES}

Andreu, L., Sarto, J.L. (2013). Financial consequences of mutual fund mergers. The European Journal of Finance.

Ayadi, R., \& De Groen, W. (2014). Banking business models monitor 2014: Europe.

Balcerzak, A.P., Kliestik, T., Streimikiene, D., \& Smrcka, L. (2017). Non-Parametric Approach to Measuring the Efficiency of Banking Sectors in European Union Countries. Acta Polytechnica Hungarica, 14(7), 51-70.

Bena, J., \& Li, K. (2014). Corporate innovations and mergers and acquisitions. The Journal of Finance, 69(5), 1923-1960.

Betzer, A., Doumet, M., Goergen, M. (2015). Disentangling the link between stock and accounting performance in acquisitions. The European Journal of Finance, 21(9), 755-771.

Bilan, Y., Mishchuk, H., \& Pylypchuk, R. (2017). Towards sustainable economic development via social entrepreneurship. Journal of Security and Sustainability Issues, 6(4), 691-702. doi:10.9770/jssi.2017.6.4(13)

Blomson, D. M. (2016). Caveat Emptor: The Accountabilities and Required Actions of Directors in Securing Value When Merging or Acquiring Companies. Paper 1 of 4: Review of Commercial or Practitioner M\&A Literature to See What Guidance this Provides Directors Involved in Transactions.

Cretin, F., Dieudonné, S., \& Bouacha, S. (2015). M\&A activity: Where are we in the cycle. Alternative Investment Analyst Review, 38-44.

Campello, M., Matta, R., \& Saffi, P. A. (2018). The rise of the equity lending market: implications for corporate policies. Available at SSRN 2703318.

Domi, S., Keco, R., Capelleras, J. L., \& Mehmeti, G. (2019). Effects of innovativeness and innovation behavior on tourism SMEs performance: The case of Albania. Economics \& Sociology, 12(3), 67-85.

Gabor, D. (2016). A step too far? The European financial transactions tax on shadow banking. Journal of European Public Policy, 23(6), 925-945.

Grigorieva, S., \& Petrunina, T. (2015). The performance of mergers and acquisitions in emerging capital markets: New evidence. Journal of Management Control, 26(4), 377-403.

Kinateder, H., Fabich, M., \& Wagner, N. (2017). Domestic mergers and acquisitions in BRICS countries: Acquirers and targets. Emerging Markets Review, 32, 190-199.

Kokoulina, A.M. (2017). The impact of corporate governance on the likelihood of mergers and acquisitions. In Achievements of University Science (pp. 127-132).

Kovacova, M., Kliestik, T., Valaskova, K., Durana, P., \& Juhaszova, Z. (2019). Systematic review of variables applied in bankruptcy prediction models of Visegrad group countries. Oeconomia Copernicana, 10(4), 743-772.

Mourdoukoutas, P. (2011). Do mergers and acquisitions enhance or destroy shareholders value?

Simionescu, M. (2016). The Competition between London companies regarding their financial performance. Journal of Competitiveness, 8(2), 5-16, doi:10.7441/joc.2016.02.01 
Simionescu, M., Lazányi, K., Sopková, G., Dobeš, K., \& Balcerzak, A. P. (2017). Determinants of economic growth in V4 countries and Romania. Journal of Competitiveness, 9(1), 103-116. doi:10.7441/joc.2017.01.07

Tang, A. C. (2015, March). Mergers and Acquisitions and its effects on firm Performance: A New Look. In Proceedings of the DLSU Research Congress.

Uhlenbruck, K., Hughes-Morgan, M., Hitt, M. A., Ferrier, W. J., \& Brymer, R. (2017). Rivals' reactions to mergers and acquisitions. Strategic Organization, 15(1), 40-66.

Zainol, N.R., Al Mamun, A., Ahmad, G., \& Simpong, D. B. (2018). Human Capital and Entrepreneurial Competencies towards Performance of Informal Microenterprises in Kelantan, Malaysia. Economics and Sociology, 11(4), 31-50. doi:10.14254/2071-789X.2018/11-4/2

Ziyadin, S., Streltsova, E., Borodin, A., Kiseleva, N., Yakovenko I., \& Baimukhanbetova, E. (2019). Assessment of investment attractiveness of projects on the basis of environmental factors. Sustainability, 11(9), 1-16. 